\title{
Delineamentos intrassujeitos nas dissertações E TESES DO PPGEES/UFSCAR
}

\author{
SINGLE-SUBJECT RESEARCH DESIGN IN THESES AND \\ DISSERTATIONS OF THE PPGEES/UFSCAR ${ }^{1}$
}

\author{
Érica A parecida Garrutti de LOURENÇO² \\ Maria Cristina Piumbato Innocentini HAYASHI ${ }^{3}$ \\ Maria Amélia de ALMEIDA ${ }^{4}$
}

\begin{abstract}
RESU M 0: os delineamentos experimentais intrassujeitos constituem importante alternativa metodológica para questionamentos inerentes às pesquisas de intervenção, desenvolvidas na Educação Especial. Em vista disso, objetivou-se identificar e caracterizar as dissertações e teses com delineamentos intrassujeitos, produzidas no Programa de Pós-Graduação em Educação Especial (PPGEEs) da Universidade Federal de São Carlos (UFSCar), desde a implementação do referido programa, em 1978, até o ano de 2004. Inicial mente, efetuou-se a leitura dos títulos, resumos e outros elementos pré-textuais das dissertações e teses para identificar as que empregaram delineamentos intrassujeitos. A seguir, coletaram-se informações sobre a caracterização da população-alvo, do tema e dos procedimentos metodológicos: tipo de delineamento intrassujeito, variáveis dependente e independente, presentes na introdução, no método e nos resultados das dissertações e teses selecionadas. Os resultados revelaram que, dentre as 21 dissertações e teses com delineamentos intrassujeitos, a maioria fez uso do delineamento A-B e do delineamento de linha de base múltipla, no total de $43 \%$ e $38 \%$, respectivamente. As demais dissertações e teses $(19 \%)$ apresentaram os delineamentos A-B-A e múltiplas sondagens. Finalizando, os delineamentos intrassujeitos podem possibilitar suficiente demonstração do controle experimental e impacto das intervenções, e sua utilização em pesquisas sobre Educação Especial pode minimizar as lacunas no conhecimento desta temática.
\end{abstract}

PALAVRAS-CHAVE: formação de pesquisadores; delineamento metodológico; produção científica discente; pesquisa intrassujeitos.

ABSTRACT: experimental single-subject research design constitutes an important methodology alternative for issues related to intervention research developed in Special Education. The objective of this study was to identify and characterize theses and dissertations that employed single-subject research design in the Graduate Program of Special Education at the Federal University of São Carlos (UFSCar), from the implementation of the referred program, in 1978, up to 2004. Initially, titles, abstracts, and other pre-text elements were scanned in theses and dissertations to identify the ones that employed single-subject research design. Next, information was collected about the characterization of the targeted public, the theme, and methodological procedures: type of design, dependent and independent variables, to be found in the introduction, method, and results of the selected theses and dissertations. The results showed that among the 21 theses and dissertations that employed single-subject design, most used A-B and multiple baseline designs, in a total of $43 \%$ and $38 \%$, respectively. The other theses and dissertations (19\%) used ABA and multiple probe designs. In conclusion, single-subject research design can effectively demonstrate experimental control and impact of interventions. Their use in Special Education research can minimize the gap in knowledge of this theme.

KEYWORDS: researcher formation; scientific methodology; student scientific production; single-subject research design.

\footnotetext{
${ }^{1}$ Special Education Graduate Program / Federal University on São Carlos (Brasil)

2 Mestre em Educação Especial, Docente do Departamento de Educação da Universidade Municipal de São Caetano do Sul - SP Brasil, egarrutti@yahoo.com.br

${ }^{3}$ Doutora em Educação. Docente do Departamento de Ciência da Informação e do Programa de PósGraduação em Educação Especial da UFSCar - SP Brasil, dmch@power.ufscar.br

${ }^{4}$ Doutora em Educação Especial. Docente do Departamento de Psicologia e do Programa de Pós-Graduação em Educação Especial da UFSCar - SP Brasil, ameliama@terra.com.br
} 


\section{INTRODUÇão}

A área educacional contempla questionamentos diversificados e os professores em seu contexto deatuação dispõem de condições que, sistematizadas e delineadas, oferecem importantes contribuições para a ciência. N esse sentido, Alberto e Troutman (2003) mencionam que os educadores podem fazer declarações sobre relações causais entre uma intervenção educacional e o desempenho do comportamento estudado desde que a coleta e a análise dos dados sejam orientadas por delineamentos metodológicos.

A articulação entre as atividades de ensino e as atividades pesquisa tem gerado importantes contribuições à área educacional, dentre as quais há o destaque para atuações relacionadas às necessidades inerentes à área, na medida em que as pesquisas emergem dos contextos naturais, da realidade escolar. As similaridades entre os comportamentos de ensino e os comportamentos de pesquisa, de acordo com Tawney e Gast (1984), estão centradas no fato de que tanto o professor quanto o pesquisador devem: a) ser capazes de identificar e analisar problemas; b) apresentar soluções criativas; c) implementar intervenção de maneira sistemática; d) documentar os efeitos dessa intervenção; e) saber como agir tendo em vista os dados coletados.

Os delineamentos metodológicos agrupam-se em duas categorias principais: os que são orientados por objetivos de natureza descritiva e os que são conduzidos por objetivos com enfoque explicativo. No primeiro caso, estão os delineamentos: descritivo, correlacional, longitudinal e ex-post-facto. No segundo caso, classificam-se os delineamentos: experimental, quase-experimental e pesquisa-ação.

Em um mapeamento da produção científica nacional sobrea Educação Especial, Nunes, Ferreira e Mendes (2004) compararam os delineamentos de dissertações e teses sobre Educação Especial, defendidas em programas de pósgraduação em Educação e Psicologia, desde 1970 até 2004. Os autores observaram o predomínio da descrição em ambas as áreas, com maior destaque na área da Educação (56\% dissertações e teses) do que na Psicologia (43\% dissertações e teses). O segundo tipo de delineamento mais frequente foi o experimental na Psicologia (17\%) e o estudo de caso na Educação (21\%) e na Psicologia (17\%).

De modo semelhante, Silva, R. (2004), mediante a análise de 27 dissertações e teses produzidas no Programa de Pós-Graduação em Educação Especial (PPGEEs) da Universidade Federal de São Carlos (UFSCar) desde a criação do referido programa, apontou que $44,4 \%$ das dissertações e teses foram descritivas, 40,7\% experimentais, 7,4\% bibliográficas e 7,4\% não especificaram o delineamento. O destaque das intervenções pode dever-se à formação dos orientadores que, mais centrada na área de Psicologia, gera maior predisposição para a realização de experimentos e quase-experimentos em decorrência do preparo oferecido nessa área. Outro fator refere-se à experiência de pesquisa acumulada no referido programa de pós-graduação. 
Especificamente em relação ao experimento e quase-experimento, assumem dois formatos: de grupos ou intrassujeitos. Nos delineamentos de grupos, os desempenhos de grupos de sujeitos são comparados, ao passo que, nos delineamentos intrassujeitos, o número de participantes é restrito e o desempenho de cada um deles é acompanhado em todas as fases do estudo.

Os delineamentos intrassujeitos são compostos por pelo menos duas condições: linha de base (A) e intervenção (B). Na linha de base, mensurações repetidas do comportamento-alvo são coletadas em situações naturais até que a tendência (sentido) e variabilidade (flutuações) dos dados estejam estáveis, devendo incluir o mínimo de três observações, mas, frequentemente incluem um número maior de mensurações. A linha de base descreve o desempenho do participante e o prediz caso a intervenção não seja aplicada. (BEST; KAHN , 1998; ALBERTO; TROUTMAN, 2003) Na intervenção, a variável independente é manipulada para a modificação do comportamento mensurado na condição de linha de base. Constituem uma alternativa às pesquisas experimentais ou quaseexperimentais em populações demasiadamente heterogêneas, tais como aquelas que formam a área da Educação Especial. Já na década de 1980, Schindele (1985) comentava sobre a heterogeneidade da população, a especificidade das intervenções e o número restrito de participantes disponíveis como principais características da referida área, características que se expandem na atualidade.

Em relação ao estudo de Nunes, Ferreira e Mendes (2004), Almeida (2003) anali sou o total de 467 resumos dissertações e teses para verificar com que frequência os delineamentos experimentais intrassujeitos foram utilizados no Brasil. Os resultados revelaram que 24 dissertações e teses empregaram esse tipo de delineamento. Desse total, a maioria (83\%) fez uso do delineamento A-B e as demais produções (17\%) utilizaram os delineamentos A-B-A e linha de base múltipla.

Desse modo, a produção científica discente analisada fez pouco uso desse delineamento, de forma a se verificar a necessidade de divulgação mais ampla desse delineamento que possibilita a explicação dos fenômenos em situações naturais.

O presente estudo tem o objetivo de identificar e caracterizar os delineamentos intrassujeitos encontrados nas dissertações e teses produzidas no PPGEEs/ UFSCar.

\section{D elineam entos intrassujeitos}

Nestetópico, são tecidas considerações sobre os tipos de delineamentos intrassujeitos, a saber: A-B e Reversão (A-B-A, A-B-A-B, B-A-B), Critério Móvel, Linha de Base Múltipla, Múltiplas Provas, Tratamentos Múltiplos, Tratamentos Alternados e Tratamentos Simultâneos. (ALBERTO; TROUTMAN, 2003; ALMEIDA, 2003; BEST; KAHN, 1998; COZBY, 2003; TAWNEY; GAST, 1984) 


\subsection{A-B e Reversão}

O Delineamento A-B é o mais básico delineamento que tem o sujeito como seu próprio controle. Todos os outros intrassujeitos são formados por variações do delineamento A-B também conhecido como del ineamento de ensino, por Alberto e Troutman (2003) e Almeida (2003). Como em todo estudo intrassujeito, " $A$ " representa as mensurações em linha de base e " $B$ " representa as mensurações que ocorrem durante o tratamento.

Conforme Poling, Methot e LeSage (1995) e Tawney e Gast (1984), diante da modificação do comportamento somente após a introdução da intervenção, há a probabilidade de que a intervenção seja a variável responsável pela alteração do comportamento. Porém, esse delineamento não possibilita a identificação da existência da relação de causa e efeito, o que o torna quaseexperimental.

Para verificar relação de causalidade, pode-se realizar a retirada da intervenção para o retorno (reversão) do comportamento à condição de linha de base (delineamento A-B-A). O Delineamento A-B-A inclui três fases: linha de base, intervenção e retirada (retorno à condição de linha de base) (COZBY, 2003; NEUMAN; MCCORMICK, 1995).

A lógica desse delineamento é que se o comportamento modifica-se na direção esperada durante a intervenção e, na retirada da intervenção, há o retorno do comportamento para níveis aproximados àqueles mensurados na linha de base inicial, pode-se afirmar, com mais certeza, que a intervenção seja a responsável pela mudança do comportamento (RICHARDS et al., 1999; TAWNEY; GAST, 1984). Os estudos podem introduzir novamente a intervenção após a fase de retirada (del ineamento A-B-A-B). Pela reinstal ação da intervenção, a demonstração do controle experimental é ainda maior e traz a vantagem de o estudo não ser encerrado em condição de linha de base, problema ético apontado pela literatura (ALM EIDA, 2003; COZBY, 2003; TAWNEY; GAST, 1984). Esse é o estudo que demonstra maior controle experimental.

Outra variação é o delineamento B-A-B, empregado nos casos em que a coleta em linha de base inicial é impossibilitada ou inapropriada. Para exemplificar, Richards e outros (1999) mencionam que seum investigador trabal ha com um indivíduo em que o comportamento resulta em mutilações de si próprio ou de outras pessoas, o delineamento B-A-B tem intervenção imediata, destituída da coleta de dados em linha de base inicial.

\subsection{Critério Móvel}

O Delineamento de Critério Móvel constitui-se das condições delinha de base e intervenção. Segundo Alberto e Troutman (2003) e Almeida (2003), a intervenção édividida em subfases queavaliam o aumento ou redução sistemática 
egradual do nível de desempenho do indivíduo por meio da alteração dos critérios de reforço, passo a passo.

O delineamento é formado por uma modificação cuidadosa nos critérios de uma precisa sequência de passos. Segundo os níveis de critérios, são introduzidas as contingências para o aumento do comportamento (por exemplo, reforço positivo ou negativo) ou a sua diminuição (por exemplo, procedimentos de reforço diferencial ou punição) (RICHARDS, et al., 1999). Em vista de que cada subfase exige maior aproximação do comportamento que se busca al cançar, emprega-se esse delineamento quando o objetivo final do programa de modificação do comportamento exige um período de tempo considerável para ser alcançado.

\subsection{Linha de Base Múltipla}

Outro delineamento intrassujeito frequente é Delineamento de Linha de Base Múltipla que permite a análise simultânea de mais de uma variável dependente, com as variações: participante, comportamento ou ambiente (ALMEIDA, 2003; ALBERTO; TROUTMAN, 2003). É apropriado para comportamentos que, uma vez aprendidos, são de difícil reversão ou quando a reversão é indesejável.

Segundo Hersen e Barlow (1976), na linha de base entre participantes, registra-se o desempenho de mais de um participante em determinado comportamento ao longo do estudo e, para cada participante, a manipulação é introduzida em momentos diferentes. N uma linha debase entre comportamentos, diferentes comportamentos de um único participante são registrados ao longo do tempo. Em diferentes momentos, aplica-se a mesma manipulação a cada um dos comportamentos. $\mathrm{N}$ a linha de base entre ambientes, determinado comportamento é registrado em ambientes variados com o mesmo participante.

Em síntese, em cada uma das três variações do delineamento delinha de base múltipla, a intervenção tem início em momentos distintos para cada participante (ambiente ou comportamento). Por exemplo, o segundo e terceiro participante são mantidos na condição de linha de base até que a intervenção com o primeiro participante tenha demonstrado efeito (modificação do comportamento); a intervenção com o terceiro participante somente é iniciada quando o efeito da intervenção com o segundo participante é alcançado e, assim sucessivamente.

\subsection{Múltiplas Sondagens}

O Delineamento de Múltiplas Sondagens é uma extensão do Delineamento de Linha de Base Múltipla. Tawney e Gast (1984) apontam que a intervenção, assim como no Delineamento de Linha de Base Múltipla, é 
sistematicamentee sequencial menteintroduzida nos comportamentos, ambientes ou participantes, em diferentes momentos.

Porém, a coleta em linha de base ocorre intermitentemente com os participantes, comportamentos ou ambientes (POLING; METHOT; LESAGE, 1995; TAWNEY; GAST, 1984). Por exemplo, a linha de base dos sujeitos que não estão sob intervenção é coletada somente quando os participantes sob intervenção atingem os critérios para cada fase. Desse modo, a coleta em linha de base ocorre em períodos alternados, sendo apropriada para estudos duradouros.

\subsection{Tratamentos Múltiplos, Alternados e Simultâneos}

Os Delineamentos de Tratamentos Múltiplos, Alternados e Simultâneos são destinados à comparação de duas ou mais intervenções. As principais variações desses delineamentos referem-se às formas como as variáveis independentes são apresentadas (TAWNEY; GAST, 1984).

O Delineamento de Tratamentos Múltiplos, segundo Alberto e Troutman (2003), também denominado de Delineamento A-B-C, investiga os efeitos dedois ou mais tratamentos em um comportamento previamentedefinido. Então, A pode representar a linha de base, $B$ indica a Intervenção 1 e $C$ representa a Intervenção 2 . Ainda, a fase $C$ pode ser uma alteração do tratamento original introduzido na fase $B$.

Tem como princi pal objetivo a determi nação de intervenções eficazes. Em vista disso, o delineamento é frequente em situações educacionais, quando o tratamento introduzido inicialmente não é eficaz e, então, outro é aplicado. De acordo com Tawney e Gast (1984), as intervenções são introduzidas sequencialmente, ou seja, o pesquisador al terna os tratamentos para cada sessão, o que dificulta o controle do efeito de uma variável independente sobre a outra (carryover effect).

O Delineamento de Tratamento Alternado também avalia a eficácia de duas ou mais intervenções, com a diferença de que evita interferências e problemas de validade associados ao Delineamento de Tratamentos Múltiplos. A principal característica é que o pesquisador seleciona al eatoriamente as sessões para cada tratamento (HOLCOMBE; WOLERY; GAST, 1994; TAWNEY; GAST, 1984). Desse modo, no caso de dois tratamentos e dez sessões, a ordem dos tratamentos pode ser 1-1-2-1-2-2-1-2-2-1. As intervenções são alternadas e equilibradas a cada sessão ao invés de blocos de sessões, assim como no Delineamento de Tratamentos Múltiplos (BEST; KAHN,1998).

O Delineamento de Tratamentos Simultâneos exige aplicação simultânea ou concorrente de duas ou mais intervenções com um único sujeito ou grupo de sujeitos. Da mesma forma que nos tratamentos alternados, no delineamento com tratamentos simultâneos, a apresentação das intervenções 
também deve ser equilibrada. Todas as intervenções estão disponíveis para o aprendiz no mesmo momento durante a fase experimental, exigindo que o aprendiz faça escolha entre as intervenções (TAWNEY; GAST, 1984).

\section{Métodos}

\subsection{FONTE DE DADOS}

A pesquisa teve como fonte de dados as dissertações e teses com delineamentos intrassujeitos produzidas no PPGEEs/ UFSCar, desde a implementação do referido programa, em 1978, até o ano de 2004. Selecionou-se esse Programa de Pós-Graduação por constituir o único em Educação Especial do Brasil e, consequentemente, concentrar relevante produção discente na área de Educação Especial.

\subsection{Procedimentos de coleta de dados}

Inicial mente, uma lista das dissertações eteses produzidas no PPGEEs foi obtida por consulta ao livro de AImeida, Mendes e Williams (2004) e aos arquivos da Secretaria da referida universidade. A seguir, foi efetuada a leitura dos resumos, registrando-se dados referenciais: autor, título, orientador, ano de defesa, linha de pesquisa e delineamento metodológico.

Dentre essas dissertações e teses, foram selecionadas aquelas que fizeram uso de delineamentos intrassujeitos, conforme os pressupostos descritos pela literatura apresentada na introdução. Para a coleta de dados nessas produções, realizou-se a leitura da introdução, do método e dos resultados. Com a leitura da introdução, identificaram-se os objetivos da pesquisa, a populaçãoalvo e o tema; com a leitura dos métodos, coletaram-se informações sobre os procedimentos metodológicos (tipo de delineamento intrassujeito, variável dependente e variável independente); e com a leitura dos resultados, obtiveramse dados sobre os procedimentos metodológicos não mencionados em tópicos anteriores (introdução e métodos) e as principais conclusões.

Em vista da necessidade de se padronizar as informações coletadas em cada produção, um protocolo construído com base em N unes et al (1999), Dias e Omote (1990), Almeida (2003) e Grácio e Garrutti (2003) foi utilizado para a coleta de dados. Desse modo, cada produção que empregou o del ineamento intrassujeito, 21 no total, foi lida e decomposta nos itens do protocolo, transcrevendo trechos das dissertações e teses que informavam sobre cada item.

\subsection{Procedimentos de ANÁlise}

Os itens do protocolo, com as informações coletadas nas dissertações e teses com delineamentos intrassujeitos produzidas no PPGEEs, identificadas pela leitura dos resumos dessas produções, foram analisados separadamente para 
agrupar as produções nas categorias (população-alvo, tema, tipo de del ineamento intrassujeito, variável dependente e variável independente).

Valendo-se desses dados, foram organizados tabelas e quadros para a caracterização das dissertações e teses com delineamentos intrassujeitos.

\section{RESULTADOS E DISCUSSÃo}

Inicialmente, são apresentados dados referentes à caracterização das dissertações e teses com delineamentos intrassujeitos (Tabelas 1 e 2). A seguir, descrevem-se os procedimentos metodológicos (Tabela 3).

Tabela 1 - Distribuição de frequências absolutas e relativas da população-alvo presente nas dissertações e teses.

\begin{tabular}{lcc}
\hline POPULAÇÃO-ALVO & $\begin{array}{c}\text { N. de Dissertações e } \\
\text { Teses }\end{array}$ & \% \\
\hline Deficiência Mental & 6 & 28 \\
Autismo & 4 & 19 \\
Deficiência Física & 3 & 14 \\
Dificuldade de Aprendizagem & 3 & 14 \\
Não Especificada & 2 & 10 \\
Deficiência Auditiva & 1 & 5 \\
Deficiência Múltipla & 1 & 5 \\
Distúrbio de Conduta & 1 & 5 \\
\hline TOTAL & 21 & 100 \\
\hline
\end{tabular}

$\mathrm{Na}$ Tabela 1, a maioria das dissertações e teses investiga questões relativas à deficiência mental e ao autismo, o que pode estar relacionado à experiência de pesquisa do corpo docente, à incidência de cada população-alvo e ao nível de atendimento educacional para cada necessidade educacional.

O PPGEEs/ UFSCar teve início em 1978 com o nome de Programa de Mestrado em Educação Especial e, desse ano até 1990, contava com a única área de concentração denominada deficiência mental. A partir de 1990, uma segunda reformulação da grade curricular do programa alterou a denominação do curso para Programa de Pós-Graduação em Educação Especial e da área de concentração para Educação do Indivíduo Especial (ALMEIDA; MENDES; WILLIAMS, 2004). Com essa reformulação, objetivou-se conferir maior abrangência ao curso, pela investigação das diversas necessidades especiais. Entretanto, conforme a Tabela 1, a abrangência da área investigada pode ser ampliada, em vista de um destaque na deficiência mental e no autismo.

Tal dado podeter al guma influência do enfoque seguido pelo PPGEEs na década de 1980 e, mais especificamente, da área de formação e experiência científica acumulada pelos docentes vinculados ao referido programa. 
Silva, M. (2004), ao identificar as áreas de formação dos docentes do PPGEEs, destaca que 68,2\% dos docentes são graduados em Psicologia, 13,7\% em Terapia Ocupacional e 18,1\% em outras áreas de conhecimento (Estudos Sociais, Enfermagem, Letras e Ciências Sociais). Em relação ao mestrado, 50\% dos docentes têm mestrado na área de Psicologia, 36,4\% na área de Educação Especial e os outros docentes (13,6\%) têm mestrado nas áreas de Educação, Saúde Mental e Saúde Coletiva. No doutorado, $68,2 \%$ dos docentes têm titulação em Psicologia, 18,1\% em Educação e 13,7\% formaram-se nas áreas de Educação Especial, Saúde Mental e Saúde Pública. Em suma, a formação dos docentes do referido programa está na área da Psicologia.

Vale ressaltar que em relação a esses dados, grande parte dos docentes do PPGEEs com doutorado em Psicologia produziu sua tese em temáticas relacionadas à Educação e, de acordo com a Coordenação de A perfeiçoamento dePessoal deN ível Superior (CAPES), esses profissionais podem compor o quadro permanente de profissionais da educação. Desse modo, o percentual de docentes do PPGEEs permanentes em Educação é de 70\%.

Quanto à incidência, a Organização Mundial da Saúde estima que $10 \%$ da população mundial têm al gum tipo de deficiência, sendo quea deficiência mental representa $5 \%$, a física $2 \%$, a auditiva $1,5 \%$, a visual $0,5 \%$ e a múltipla $1 \%$. A maior incidência da deficiência mental pode ser um fator que direcione o interesse por questões relacionadas a tal população-alvo.

No que se refere à educação de alunos com necessidades especiais, o Censo Escolar de 2005 realizado pelo Ministério da Educação (MEC) e Instituto Nacional de Estudos Pedagógicos (INEP) revela que 43,4\% das matrículas na Educação Especial em 2005 são de al unos com deficiência mental. A seguir, estão as necessidades especiais: condutas típicas com 12,4\%, deficiência múltipla com $10,5 \%$, baixa visão com $8,5 \%$, surdez com $7,2 \%$, deficiência física com $5,8 \%$, deficiência auditiva com 3\%, síndrome de Down com 5,4\%, autismo com 1,5\%, cegueira com 1,3\% entre outras necessidades especiais. Desse modo, a deficiência mental é a que constitui o maior número de matrículas.

Tabela 2 - Distribuição de frequências absolutas e relativas dos temas presentes nas dissertações e teses.

\begin{tabular}{lcc}
\hline TEMA & $\begin{array}{c}\text { N. de Dissertações e } \\
\text { Teses }\end{array}$ & \% \\
\hline Recursos humanos & 6 & 28 \\
Linguagem e cognição & 6 & 28 \\
Habilidades acadêmicas & 3 & 14 \\
Profissionalização & 2 & 10 \\
Saúde e reabilitação & 2 & 10 \\
Relações interpessoais & 2 & 10 \\
\hline TOTAL & 21 & 100 \\
\hline
\end{tabular}


A Tabela 2 mostra que a maior parte da produção científica discente enfoca os temas: formação de recursos humanos e linguagem e cognição de pessoas com necessidades especiais. Justifica-se a relevância desses temas na Educação Especial ao considerar que, para se investir no desempenho de pessoas com necessidades especiais, faz-se necessária a capacitação de recursos humanos com possi bilidade de direcionar um trabal ho pedagógico de qual idade. Em relação à linguagem cognição, o enfoque está na caracterização do repertório comunicativo de pessoas com necessidades educacionais especiais, bem como no desenvolvimento e avaliação de intervenções junto a essa população. Para que qualquer trabalho educacional seja efetivo, deve existir um meio de comunicação entre as partes.

Quanto aos demais temas (habilidades acadêmicas, saúde e reabilitação, profissionalização e relações interpessoais), é importante que suas abordagens sejam estimuladas nas dissertações e teses com delineamentos intrassujeitos.

Tabela 3 - Distribuição de frequências absolutas e relativas dos delineamentos intrassujeitos presentes nas dissertações e teses.

\begin{tabular}{lcc}
\hline DELINEAMENTO & $\begin{array}{c}\text { N. de Dissertações e } \\
\text { Teses }\end{array}$ & \% \\
\hline Linha de Base Múltipla & 9 & 43 \\
A-B & 8 & 38 \\
A-B-A & 3 & 14 \\
Múltiplas Sondagens & 1 & 5 \\
\hline TOTAL & 21 & 100 \\
\hline
\end{tabular}

Conformea Tabela 3, grande parte das dissertações e teses analisadas faz uso dos delineamentos A-B e linha de base múltipla (43\% e $38 \%$, respectivamente). Esse enfoque pode dever-se aos próprios questionamentos delimitados nas produções. Por exemplo, ao se tratar de questões relacionadas ao ensino-aprendizagem, os delineamentos A-B e linha de base múltipla geral mente são utilizados, já que não requerem a reversão dos comportamentosalvo para níveis semelhantes àqueles apresentados na condição de linha de base.

O intrassujeito A-B é o que mais se aproxima das condições naturais desala deaula. O professor avalia o conhecimento do al uno-alvo preliminarmente e, após o planejamento, aplica a intervenção, controlando variáveis al ternativas, por exemplo, sexo, idade, turno, etc. Nesse processo, a principal dificuldade do professor será a sistematização da pesquisa, mediante a coleta de mensurações repetidas na linha de base e intervenção. 
Os dados de Almeida (2003), que analisou os delineamentos experimentais intrassujeitos de dissertações e teses produzidas em programas de pós-graduação do Brasil, são semelhantes aos da Tabela 3. Tais resultados revelaram que a mai oria das dissertações e teses (83\%) fez uso do delineamento A-B. As demais produções (17\%) utilizaram os delineamentos A-B-A e linha de base múltipla.

\section{Detalhando as dissertações e teses do PPGEEs/ UFSCar que} apresentam delineamentos intrassujeitos, seguem os Quadros 1, 2 e 3.

\begin{tabular}{|c|c|c|c|c|}
\hline Cód. & Objetivo & V. D.* & V. I.* & Resultados \\
\hline 1 & $\begin{array}{l}\text { Avaliar um programa de } \\
\text { orientação para mães } \\
\text { quanto à integração de seus } \\
\text { filhos com deficiência } \\
\text { mental }\end{array}$ & $\begin{array}{l}\text { Atividades de lar } \\
\text { realizadas pelos filhos } \\
\text { com deficiência mental }\end{array}$ & $\begin{array}{l}\text { Programa de } \\
\text { orientação às mães }\end{array}$ & $\begin{array}{l}\text { Ocorreram mudanças } \\
\text { desejáveis nos } \\
\text { comportamentos dos filhos, } \\
\text { em vista da evolução e } \\
\text { permanência dos resultados } \\
\text { no "follow-up". }\end{array}$ \\
\hline 2 & $\begin{array}{l}\text { Avaliar os efeitos da } \\
\text { Educação Física sobre a } \\
\text { alfabetização de alunos } \\
\text { com deficiência mental }\end{array}$ & $\begin{array}{l}\text { Desempenho na Prova } \\
\text { das } 4 \text { palavras e uma } \\
\text { frase }\end{array}$ & $\begin{array}{l}\text { Atividades de } \\
\text { recreação em aulas } \\
\text { de Educação Física e } \\
\text { alfabetização }\end{array}$ & $\begin{array}{l}\text { Os participantes } \\
\text { apresentaram evolução em } \\
\text { suas classificações na Prova. } \\
\text { Para alguns alunos, o } \\
\text { processo foi acelerado. }\end{array}$ \\
\hline 3 & $\begin{array}{l}\text { Avaliar os efeitos de um } \\
\text { programa de Ensino sobre o } \\
\text { desenvolvimento de } \\
\text { habilidades motoras } \\
\text { aquáticas em lesados } \\
\text { medulares }\end{array}$ & $\begin{array}{l}\text { Níveis de aprendizagem } \\
\text { (ambientação, domínio } \\
\text { do meio líquido, } \\
\text { exercícios terapêuticos } \\
\text { e condicionamento } \\
\text { orgânico global) }\end{array}$ & $\begin{array}{l}\text { Treinamento de } 26 \\
\text { comportamentos } \\
\text { motores aquáticos, } \\
\text { pela Hidroterapia em } \\
\text { piscina aquecida }\end{array}$ & $\begin{array}{l}\text { Obteve-se nível médio de } \\
\text { aprendizagem acima de } 80 \% \\
\text { em } 20 \text { dos } 26 \\
\text { comportamentos motores } \\
\text { aquáticos. Os participantes } \\
\text { apresentaram independência } \\
\text { na piscina. }\end{array}$ \\
\hline 4 & $\begin{array}{l}\text { Avaliar um programa de } \\
\text { capacitação profissional } \\
\text { para pessoas com } \\
\text { deficiência mental em } \\
\text { ambiente natural } \\
\end{array}$ & $\begin{array}{l}\text { Pontos obtidos, tempo } \\
\text { gasto e tipos de ajuda } \\
\text { recebidos na execução } \\
\text { das tarefas }\end{array}$ & $\begin{array}{l}\text { Intervenção realizada } \\
\text { mediante o ensino de } \\
\text { tarefas de trabalho }\end{array}$ & $\begin{array}{l}\text { O tempo de execução em } \\
\text { relação ao trabalhador não- } \\
\text { deficiente foi semelhante na } \\
\text { maioria das tarefas. }\end{array}$ \\
\hline 5 & $\begin{array}{l}\text { Verificar se a intervenção } \\
\text { planejada favorece a } \\
\text { participação do deficiente } \\
\text { mental severo em uma } \\
\text { tarefa de trabalho }\end{array}$ & $\begin{array}{l}\text { Tempo de engajamento } \\
\text { na tarefa, instruções } \\
\text { verbais, ajudas físicas e } \\
\text { passos completados da } \\
\text { tarefa }\end{array}$ & $\begin{array}{l}\text { Treino de trabalho } \\
\text { com material } \\
\text { instrucional, seguido } \\
\text { de níveis de instrução } \\
\text { e reforçamento }\end{array}$ & $\begin{array}{l}\text { Ocorreu engajamento dos } \\
\text { participantes nas tarefas. As } \\
\text { instruções foram } \\
\text { esvanecidas, exceto em P1. } \\
\text { A produtividade ocorreu } \\
\text { para P2 e P3. }\end{array}$ \\
\hline 6 & $\begin{array}{l}\text { Avaliar os efeitos da } \\
\text { adaptação do PECS sobre a } \\
\text { comunicação de pessoas } \\
\text { com autismo, sem } \\
\text { linguagem oral funcional }\end{array}$ & $\begin{array}{l}\text { Tipos de apoio, } \\
\text { tentativas nos treinos do } \\
\text { PECS-Adapatado, } \\
\text { vocabulário de } \\
\text { palavras, sons e figuras }\end{array}$ & $\begin{array}{l}\text { Treino da } \\
\text { comunicação por } \\
\text { meio do PECS- } \\
\text { Adaptado }\end{array}$ & $\begin{array}{l}\text { Os participantes } \\
\text { modificaram a comunicação } \\
\text { e adquiriram vocabulário } \\
\text { expressivo de algumas } \\
\text { palavras, sons e figuras. }\end{array}$ \\
\hline 7 & $\begin{array}{l}\text { Analisar os efeitos de um } \\
\text { sistema de frequência } \\
\text { modulada sobre a atenção, } \\
\text { a distração e o desempenho } \\
\text { de crianças com déficit de } \\
\text { atenção }\end{array}$ & $\begin{array}{l}\text { Comportamentos de } \\
\text { atenção e distração e } \\
\text { desempenho acadêmico }\end{array}$ & $\begin{array}{l}\text { Sistema de } \\
\text { frequência modulada } \\
\text { pessoal }\end{array}$ & $\begin{array}{l}\text { Aumentou a atenção e } \\
\text { diminuiu a distração. As três } \\
\text { crianças foram promovidas } \\
\text { para as séries escolares } \\
\text { seguintes após a intervenção. }\end{array}$ \\
\hline 8 & $\begin{array}{l}\text { Capacitar duas atendentes } \\
\text { para o ensino de crianças na } \\
\text { realização de tarefas em } \\
\text { suas rotinas diárias }\end{array}$ & $\begin{array}{l}\text { Passos de tarefas } \\
\text { realizadas pelas } \\
\text { atendentes e crianças e } \\
\text { níveis de ajuda } \\
\text { oferecidos às crianças. }\end{array}$ & $\begin{array}{l}\text { Capacitação para o } \\
\text { ensino de tarefas de } \\
\text { cuidados pessoais, } \\
\text { com níveis de ajuda } \\
\text { diferenciados }\end{array}$ & $\begin{array}{l}\text { As atendentes ofereceram } \\
\text { níveis de ajuda que } \\
\text { promoveram maior } \\
\text { independência às crianças e } \\
\text { deixaram de fazer tarefas } \\
\text { pelas crianças. }\end{array}$ \\
\hline
\end{tabular}

\section{Quadro 1 - Dissertações e teses com delineamento A-B.}

*VD: variável dependente; VI: variável independente. 
Em todas as dissertações e teses do Quadro 1, o delineamento A-B é o que melhor representa os objetos estudados, já que são formados por comportamentos de difícil reversão.

Por exemplo, ao se implementar um programa de intervenção para mães direcionado ao desenvolvimento de habilidades para a integração social de seus filhos (Estudo 1), os comportamentos apreendidos dificilmente retornariam aos níveis iniciais delinha de base. Do mesmo modo, no Estudo 2, ao sealfabetizar alunos com o auxílio de atividades recreativas, dificilmente suas habilidades retornariam aos níveis observados na condição de linha de base, mediante a retirada da intervenção. Essas características inviabilizam o emprego dos delineamentos de reversão (A-B-A, B-A-B, A-B-A-B).

Ainda que a reversão seja possível, deve-se analisar as implicações éticas princi palmente nos casos em que o retorno do comportamento ao nível de linha de base gere prejuízo ao participante. As implicações éticas da reversão acentuam-se quando o estudo envolve comportamentos de agressividade e mutilações do corpo pelos próprios participantes, ao se requerer intervenções imediatas e contínuas.

Segundo Yaden (1995), para a sel eção dos del ineamentos de reversão, dois aspectos devem ser considerados: a natureza do comportamento e a estabilidade da linha de base. Deve-se verificar, se o comportamento tem ou não probabilidade de retornar ao nível de linha de base, diante da remoção da intervenção. Comportamentos que envolvem aspectos cognitivos dificilmente são revertidos e, nesses casos, dificulta-se a verificação de relações causais por esse delineamento. A linha de base deve ser estável para viabilizar a demonstração do impacto da intervenção. No intrassujeito A-B, mediante a estabilidade dos escores coletados na linha de base e modificação significativa do comportamento somente após a intervenção, há probabilidade de que as modicações ocorridas sejam efeito da aplicação da intervenção. Ainda sim, esse delineamento não permite verificar relações causais, pois variáveis alternativas (maturação, testagem, mortalidade, instrumentação) podem concorrer com a intervenção.

Do mesmo modo que o delineamento $A-B$, o de linha de base múltipla não requer o retorno do desempenho para condições próximas às de linha de base, o que se mostra favorável às questões relacionadas à cognição, conforme ocorre na maioria dos estudos do Quadro 1. Entretanto, há a desvantagem de que o segundo e o terceiro participantes (comportamentos ou ambientes) permanecem na condição de linha de base até que o desempenho do primeiro participante alcance o critério delimitado pelo pesquisador. Talvez esse seja um fator que tenha levado os autores das dissertações e teses do Quadro 1 a não optarem pela linha de base múltipla. Por exemplo, para a adaptação do PECsA daptado beneficiar a comunicação de pessoas com autismo no Estudo 6, o tempo de espera dos participantes dois etrês seria muito grande, o que teria implicações éticas. 
Além do tempo, outro fator é o da convivência. O contato prévio entre os participantes pode influenciar nos dados gerados, já que um participante pode informar os outros sobre os procedimentos de intervenção. Por exemplo, para desenvolver habilidades motoras aquáticas independentes em lesados medulares pela Hidroterapia (Estudo 3), o fato de os participantes frequentarem um ambiente comum, a clínica de reabilitação, com possibilidade decomunicação, pode constituir uma hipótese al ternativa para os resultados do estudo.

\begin{tabular}{|l|l|l|l|l|}
\hline Cód. & \multicolumn{1}{|c|}{ Objetivo } & \multicolumn{1}{c|}{ V. D.* } & \multicolumn{1}{c|}{ V. I.* } & \multicolumn{1}{c|}{ Resultados } \\
\hline 1 & $\begin{array}{l}\text { Avaliar um treinamento } \\
\text { voltado para o } \\
\text { desenvolvimento das } \\
\text { habilidades de consciência } \\
\text { fonológica }\end{array}$ & $\begin{array}{l}\text { Habilidades (análise, } \\
\text { síntese, manipulação } \\
\text { e transposição } \\
\text { silábica/ fonêmica) }\end{array}$ & $\begin{array}{l}\text { Treino das habilidades } \\
\text { de consciência } \\
\text { fonológica, utilizando } \\
\text { palavras, sílabas e } \\
\text { fonemas }\end{array}$ & $\begin{array}{l}\text { Obteve-se melhora no } \\
\text { desempenho de todas as } \\
\text { habilidades treinadas, } \\
\text { embora com índice menor } \\
\text { na manipulação de } \\
\text { fonemas. }\end{array}$ \\
\hline 2 & $\begin{array}{l}\text { Verificar os efeitos de um } \\
\text { treinamento para mães } \\
\text { sobre o ensino de } \\
\text { habilidades de leitura e } \\
\text { escrita de seus filhos com } \\
\text { deficiência mental. }\end{array}$ & $\begin{array}{l}\text { Desempenho nas } \\
\text { relações AF, AC, } \\
\mathrm{AB}, \mathrm{BC}, \mathrm{CD}, \mathrm{AD}, \\
\mathrm{BD}, \mathrm{CE} \mathrm{e} \mathrm{BE}\end{array}$ & $\begin{array}{l}\text { Treino das relações de } \\
\text { cópia e ditado }\end{array}$ & $\begin{array}{l}\text { Ocorreu a aquisição do } \\
\text { repertório, mediante as } \\
\text { variáveis intervenientes: } \\
\text { efetividade do ensino pelas } \\
\text { mães, tempo entre ensino e } \\
\text { teste e número de } \\
\text { tentativas. }\end{array}$ \\
\hline 3 & $\begin{array}{l}\text { Analisar as condições } \\
\text { favorecedoras da formação } \\
\text { de classes de equivalência e } \\
\text { interpretar processos que } \\
\text { interferem na formação de } \\
\text { classes }\end{array}$ & $\begin{array}{l}\text { Acertos nas tarefas } \\
\text { de treino e teste das } \\
\text { relações }(\mathrm{AB}, \mathrm{AC}, \\
\text { AD, etc) }\end{array}$ & $\begin{array}{l}\text { Estrutura dos treinos, } \\
\text { dimensões dos } \\
\text { estímulos ou mudanças } \\
\text { nas contingências }\end{array}$ & $\begin{array}{l}\text { A mudança pode } \\
\text { ser altamente crítica na } \\
\text { apresentação de respostas } \\
\text { de observar e no } \\
\text { subseqüente aumento dos } \\
\text { comportamentos de } \\
\text { escolha. }\end{array}$ \\
\hline
\end{tabular}

Quadro 2 - Dissertações e teses com delineamento A-B-A.

*VD: variável dependente; VI: variável independente.

No Quadro 2, os três estudos aproximam-se do intrassujeito A-B-A. Entretanto, os comportamentos contemplados são de difícil reversão, pois envolvem o ensino e a aprendizagem de habilidades acadêmicas e linguagem. $O$ retorno dos índices de desempenho para níveis próximos aos de linha de base constitui um aspecto de difícil observação nos resultados gerados.

Ainda, a coleta de dados que avalia os comportamentos-alvo em cada estudo nas suas diferentes etapas, segue uma perspectiva diferente do que se especifica para o delineamento A-B-A. Nas dissertações analisadas, ocorre a aplicação de testes diferentes para verificar a emergência de relações variadas em cada etapa do estudo. Desse modo, as estruturas desses estudos mais se aproximam do delineamento de critério móvel do que do delineamento A-B-A. Os participantes são avaliados em etapas contínuas e os treinamentos são introduzidos de modo gradual e sistemático. Richard et al (1999) afirmam que, no delineamento de critério móvel, há a modificação cuidadosa de critérios distribuídos em uma sequência de passos para a introdução de contingências que possibilitam o aumento ou a diminuição do comportamento. 
Convêm ressaltar que, essa é uma especificidade das produções do PPGEEs que se pautam na análise experimental e, especificamente, no paradigma da equivalência de estímulos. Esse paradigma é definido como o responder relacional emergente que apresenta as propriedades de reflexividade, simetria e transitividade (HAYDU, 2003; ROSSIT; FERREIRA, 2003).

\begin{tabular}{|c|c|c|c|c|}
\hline Cód. & Objetivo & V.D.* & V. I.* & Resultados \\
\hline 1 & $\begin{array}{l}\text { Verificar se recursos } \\
\text { musicais interferem na } \\
\text { conduta de cuidadores de } \\
\text { crianças de } 0 \text { a } 3 \text { anos em } \\
\text { creches, distantes da mãe }\end{array}$ & $\begin{array}{l}\text { Ocorrências de } \\
\text { manipulação com aviso } \\
\text { às crianças, nomeação de } \\
\text { partes do corpo e cantos } \\
\text { no banho }\end{array}$ & $\begin{array}{l}\text { Programa de ensino } \\
\text { aplicado às cuidadoras } \\
\text { para a interação com } \\
\text { bebês durante } \\
\text { situações de banho, } \\
\text { mediante a utilização } \\
\text { de canções }\end{array}$ & $\begin{array}{l}\text { Houve baixa frequência de } \\
\text { mudanças nas condutas } \\
\text { sobre sinalização de } \\
\text { manipulações e para } \\
\text { aprendizagem dos bebês } \\
\text { acerca de seu próprio corpo. }\end{array}$ \\
\hline 2 & $\begin{array}{l}\text { Promover aumento da } \\
\text { extensão média dos } \\
\text { enunciados pelo uso de } \\
\text { habilidades } \\
\text { comunicativas verbais }\end{array}$ & $\begin{array}{l}\text { Número da extensão } \\
\text { média dos enunciados e } \\
\text { habilidades narrativo- } \\
\text { discursivas por minuto }\end{array}$ & $\begin{array}{l}\text { Aplicação de } \\
\text { conversas espontâneas, } \\
\text { atividades com } \\
\text { dificuldades de } \\
\text { linguagem, jogos, } \\
\text { solicitações de relatos } \\
\text { e atividades } \\
\text { metalinguísticas }\end{array}$ & $\begin{array}{l}\text { Com os três participantes, } \\
\text { aumentou-se a extensão } \\
\text { média dos enunciados e o } \\
\text { uso de habilidades } \\
\text { narrativo-discursivas. }\end{array}$ \\
\hline 3 & $\begin{array}{l}\text { Avaliar intervenção } \\
\text { dirigida aos pais e } \\
\text { professores para reduzir a } \\
\text { agressividade de crianças } \\
\text { e incrementar seus } \\
\text { comportamentos } \\
\text { socialmente adaptados }\end{array}$ & $\begin{array}{l}\text { Frequência de } \\
\text { comportamentos de } \\
\text { agressão na escola, por } \\
\text { sessão }\end{array}$ & $\begin{array}{l}\text { Com as crianças, } \\
\text { tratou-se de regras, } \\
\text { seguimento de } \\
\text { instruções, resolução } \\
\text { dos conflitos. } \\
\text { Capacitou as mães para } \\
\text { lidarem com os filhos e } \\
\text { auxiliou as professoras } \\
\text { no manejo com os } \\
\text { alunos }\end{array}$ & $\begin{array}{l}\text { Em geral, as crianças } \\
\text { diminuíram a agressividade. } \\
\text { As mães aumentaram a } \\
\text { qualidade de suas relações } \\
\text { com seus filhos. Com as } \\
\text { professoras, diante da } \\
\text { pesquisadora, ocorreu } \\
\text { melhora. }\end{array}$ \\
\hline 4 & $\begin{array}{l}\text { Investigar se o sistema } \\
\text { PECS-Adaptado, } \\
\text { associado às figuras do } \\
\text { PCS, influencia a } \\
\text { comunicação de crianças } \\
\text { com paralisia cerebral e } \\
\text { seus interlocutores }\end{array}$ & $\begin{array}{l}\text { Pontuações na realização } \\
\text { de solicitações segundo o } \\
\text { nível de ajuda (sem êxito, } \\
\text { com auxílio físico, } \\
\text { auxílio verbal e } \\
\text { independência) }\end{array}$ & $\begin{array}{l}\text { Intervenção centrada } \\
\text { em trocas, aumento da } \\
\text { espontaneidade, } \\
\text { discriminação das } \\
\text { figuras, redução do } \\
\text { tamanho das mesmas, } \\
\text { formação de sentenças } \\
\text { e vocabulário }\end{array}$ & $\begin{array}{l}\text { Os três participantes } \\
\text { conseguiram comunicar } \\
\text { suas necessidades por meio } \\
\text { das figuras. P1 fez trocas } \\
\text { intencionais. P2 e P3 } \\
\text { emitiram sons guturais ou } \\
\text { palavras dissílabas. }\end{array}$ \\
\hline 5 & $\begin{array}{l}\text { Avaliar a dramatização de } \\
\text { histórias infantis para a } \\
\text { compreensão da } \\
\text { linguagem oral de } \\
\text { crianças com deficiência } \\
\text { auditiva }\end{array}$ & $\begin{array}{l}\text { Conhecimento da } \\
\text { História, antes e após } \\
\text { aplicações de atividades } \\
\text { pedagógicas e de } \\
\text { dramatização }\end{array}$ & $\begin{array}{l}\text { Habilidades de } \\
\text { consciência } \\
\text { fonológica, via } \\
\text { atividade pedagógica e } \\
\text { dramatização referente } \\
\text { à História }\end{array}$ & $\begin{array}{l}\text { Melhorou o desempenho da } \\
\text { compreensão oral da } \\
\text { História, após a introdução } \\
\text { da atividade de apoio } \\
\text { pedagógico e da } \\
\text { dramatização. }\end{array}$ \\
\hline 6 & $\begin{array}{l}\text { Verificar o impacto da } \\
\text { aprendizagem de } \\
\text { comportamentos iniciais } \\
\text { ao programar ensino a } \\
\text { professores que atendem } \\
\text { indivíduos especiais sobre } \\
\text { o ensino de arte. }\end{array}$ & $\begin{array}{l}\text { Comportamentos de } \\
\text { ensinar arte (ministrar } \\
\text { aula, adaptar recursos, } \\
\text { etc) e seus valores } \\
\text { (curricular, institucional, } \\
\text { pesquisa, etc) }\end{array}$ & $\begin{array}{l}\text { Programa de } \\
\text { aprendizagem de } \\
\text { comportamentos } \\
\text { iniciais de programar } \\
\text { ensino, formado por } \\
\text { quatro módulos }\end{array}$ & $\begin{array}{l}\text { Aprender comportamentos } \\
\text { de programar ensino } \\
\text { influencia no ensinar Arte. } \\
\text { A eficácia da capacitação } \\
\text { depende dos conhecimentos } \\
\text { prévios, trabalho e } \\
\text { compreensão sobre sua } \\
\text { função. }\end{array}$ \\
\hline 7 & $\begin{array}{l}\text { Promover melhor } \\
\text { interação entre mãe e } \\
\text { criança com deficiência } \\
\text { mental, quanto à } \\
\text { estimulação de seus filhos } \\
\text { e qualidade da interação }\end{array}$ & $\begin{array}{l}\text { Comportamentos de } \\
\text { interação mãe-criança e } \\
\text { favorecedores do } \\
\text { desenvolvimento infantil, } \\
\text { fornecimento dicas e } \\
\text { ajuda física }\end{array}$ & $\begin{array}{l}\text { Intervenção com a } \\
\text { família e a criança, } \\
\text { mediante a promoção } \\
\text { de uma melhor } \\
\text { interação entre mãe e } \\
\text { criança }\end{array}$ & $\begin{array}{l}\text { Os comportamentos das } \\
\text { mães foram alterados num } \\
\text { tempo exíguo em condições } \\
\text { adversas: precariedade } \\
\text { financeira, baixa instrução, } \\
\text { violência doméstica e pouco } \\
\text { apoio. }\end{array}$ \\
\hline
\end{tabular}

Quadro 3 - Dissertações e teses com delineamento de linha de base múltipla.

* VD: variável dependente; VI: variável independente. 
As dissertações e teses que fazem uso desse delineamento cruzam, em geral, o desempenho de participantes. No Estudo 4, para investigar os efeitos do uso sistema PECS-Adaptado, associado às figuras do PCS, são selecionados três participantes que, inicialmente, são mantidos em linha debase até se adquirir a tendência e a estabilidade da linha de base. A pós, inicia-se a aplicação da intervenção com o primeiro participante e, concomitantemente, os demais são mantidos em linha de baseatéqueo primeiro tenha o obtido desempenho próximo ao que se pretende com a intervenção. Tanto os participantes mantidos em linha de base como os que estão em intervenção são observados frequentemente, gerando as mensurações repetidas. Essas mensurações são apresentadas no modelo de gráfico de linha de modo a apresentar a tendência e variabilidade do comportamento nas diversas fases do estudo.

Com exceção do Estudo 5, todos os apresentados no Quadro 3 seguem o modelo do Estudo 4, ou seja, são formados por mensurações repetidas. A autora do Estudo 5 especifica o delineamento de linha de base múltipla em sua dissertação, mas, a coleta de dados na linha de base e na intervenção segue o modelo de pré e pós-teste. O desempenho dos participantes foi observado em dois momentos: antes e após a intervenção. Entretanto, a linha de base múltipla requer mensurações contínuas para sevisual izar a modificação do comportamento em qualquer etapa, pois outros fenômenos, simultâneos à intervenção, podem ter influência no desempenho dos participantes.

Em relação aos cruzamentos entre comportamentos e ambientes, apenas duas dissertações fazem uso dessas modalidades (Estudos 7 e 8). Esse fato pode estar relacionado à dificuldade de se garantir validade externa por meio dessas modalidades. Para a general ização dos resultados, o ideal éque outros dois participantes sejam comparados em cada comportamento (ou ambiente), porque os dados na linha de base múltipla que cruza comportamentos (ou ambientes) são coletados com apenas um participante.

O Estudo 7 supera essa dificul dade ao investigar os comportamentos indicativos da interação mãe-criança e favorecedores do desenvolvimento infantil (fornecer comentários positivos, rotular objetos, fazer questões) com três participantes. Desse modo, replica-se o cruzamento entre comportamentos realizado com um participante em dois outros participantes.

O Estudo 8, por sua vez, cruza os dados provenientes de um participante em três ambientes, a saber: casa, escola e mercado. Provavelmente, esse estudo tenha apenas um participanteem decorrência da dificuldade de serem selecionados outros participantes com características semelhantes, já que a necessidade especial abordada, o autismo, tem menor incidência que, por exemplo, crianças não-deficientes.

Embora o delineamento de múltiplas sondagens, que constitui uma variação da linha de base múltipla, seja utilizado em apenas uma dissertação, vale ressaltar sua importância para as pesquisas relacionadas à Educação Especial . 
Esse delineamento éapropriado principalmentenos casos em queo estudo envolve diferentes participantes (pais, alunos e profissionais, por exemplo) e um período de coleta de dados extenso, o que exigiria um trabal ho exaustivo do pesquisador mediante a coleta de dados contínua com os participantes que são mantidos em linha de base. Talvez a menor incidência das múltiplas sondagens deva-se ao desconhecimento das particularidades desse delineamento na produção científica.

\section{CONCLUSÕES}

Os resultados revelaram que, dentre as dissertações e teses com delineamentos intrassujeitos, a maioria faz uso do delineamento A-B e da linha de base múltipla, cada um com 43\% e 38\%. As demais dissertações e teses (19\%) apresentam os delineamentos: A-B-A e Múltiplas Sondagens.

A heterogeneidade da população-alvo da Educação Especial e a consequente dificuldade na seleção de indivíduos para a composição de delineamentos de grupo, de certo modo, direcionam o interesse pelos delineamentos intrassujeitos. Em decorrência da dificuldade da formação de grupos de comparação, os efeitos de diferentes tratamentos aplicados aos mesmos participantes em diferentes momentos são comparados e, concomitantemente, focaliza-se o desempenho individual ao longo de toda a pesquisa.

Além do acima mencionado, o delineamento intrassujeitos permite que se caminhe em direção a superação da distância entre pesquisa e prestação de serviços, já que se aplica em situações naturais (escolas, clínicas, hospitais e lares) e áreas diferentes (Educação, Psicologia, Educação Especial e outras).

Finalizando, os delineamentos experimentais intrassujeitos (Reversão, Critério Móvel, Linha de Base Múltipla e Múltiplas Provas e Tratamentos Alternativos) possibilitam suficiente demonstração do controle experimental e impacto das intervenções, aspecto que indica a importância do estímulo à sua utilização em pesquisas da Educação Especial. O Delineamento A-B, considerado "Delineamento de Ensino" também deve ter sua utilização estimulada nas pesquisas em Educação Especial, tendo em vista que pode fornecer demonstração convincente de que as modificações no comportamento estejam relacionadas à determinada intervenção.

\section{Referências}

ALBERTO, P. A.; TROUTMAN, A.C. Single-Subject Designs. In: an alysis for teachers. Columbus, Ohio: Merrill Prentice Hall, 2003. p. 167-227.

. A pplied behavior

ALMEIDA, M. A. M etodologia de del ineamentos de pesquisa experimental intra-sujeitos: relato dealguns estudos conduzidos no Brasil. In: MARQUEZINE, M. C.; ALMEIDA, M. A.; 
OMOTE, S. Colóquios sobre pesquisa em edu cação especial. Londrina: Eduel, 2003. p. 63-99.

ALMEIDA, M. A.; MENDES, E. G.; WILLIAMS, L. C. A. (Org.). Programa de pós graduação em Educação E special: Resumos de teses e dissertações. São Carlos: EdUFSCar, 2004.

BEST, J.W.; KAHN, J.V. Single-subject experimental research. In: Research in E ducation. 8 ed. Singapore: Allyn \& Bacon, 1998. p. 209-227.

COZBY, P. C. M étodos de pesquisa em ciências do comportamento. São Paulo: A tlas, 2003.

DIAS, T.; OMOTE, S. A entrevista em Educação Especial: natureza dos problemas investigados. In. DIAS, T. R. S. MENDES, E. G.; DEN ARI, F. E.; REIS, M.J. D.; COSTA, M. P. R. (Org.). Temas em E ducação Especial 1. São Carlos: UFSCar, 1990. p.67-80.

GRÁCIO, M.C.C.; GARRUTTI, E.A. A disciplina Estatística na área de Educação: seleção e organização deconteúdos. Educação M atemática em R evista-RS, Osório, n. 5, p. 12-20, 2003.

HAYDU, V. B. O queéequivalência deestímulos? In Costa, C. E.; LUZIA , J. C.; SANTAN NA, H. H. N. (Org). Primeiros passos em anál ise do comportamento e cognição. Santo A ndré, 2003. v. 1, p. 55-64.

HERSEN, M.; BARLOW, D. H. Single Case Experimental Designs: Strategies for Studying Behavior Change. N ew York: Pergamon Press, 1976.

HOLCOMBE, A.; WOLERY, M.; GAST, D. L. Comparativesinglesubject research: descripition of designs and discussion of problems. Topics in Early Childhood Special Education, Estados Unidos, v. 14, n. 1, p. 119-145, 1994.

NEUMAN, S. B.; McCORMIK, S. Singlesubject experimental research: applications for literacy. Delaware: International Reading Association, 1995.

NUNES, L.R.O.P.; FERREIRA, J.R.; GLAT, R.; MENDES, E.G. A pós-graduação em educação especial no Brasil: anál isecrítica da produção discente. R evista Brasileir ra deE ducação Especial . M arília, v.3, n.5, p. 113-126, 1999.

NUNES, L. R. O. P.; FERREIRA, J. R.; MENDES, E. G. A produção discenteda pós-graduação em Educação ePsicologia sobre os indivíduos com necessidades educacionai s especiais. In: MENDES, E. G.; ALMEIDA, M. A.; WILLIAMS, L. C. A. Temas em Educação Especial : avanços recentes. São Carlos: EdUFSCar, 2004. p.131-142.

POLING, A.; METHOT, L. L.; LESA GE, M. G. Fundamentals of behavior analytic research. New York and London: Plenum Press, 1995.

RICHARDS, S. B., TAYLOR, R. L., RAMASAMY, R.; RICHARDS, R. Single subject research: applications in educational and clinical settings. San Diego: Singular Publishing Group, 1999.

ROSSIT, R. A. S.; FERREIRA, P. R. S. Equivalência de estímulos e o ensino depré-requisitos monetários para pessoas com deficiência mental. Temas em P sicologia SBP, Ribei rão Preto, v. 21, n. 2, p. 97-106, 2003.

SCHINDELE, R. A. Research methodology in special education: a framework approach to special problems and solutions. In: HEGARTY, S.; EVANS, P. (ed.) R esearch and evaluation methods in Special Education: quantitative and qualitative techniques in case study work. WindsorBerks: N fer-N elson, 1985. p.3-26. 
SILVA, M. R. A nálisebibliométrica da produ ção científica docente do Programa deP ós G raduação em Educação Especial da U FSCar. 2004. 177 f. Dissertação (M estrado em Educação Especial) Universidade Federal de São Carlos, São Carlos, 2004

SILVA, R. H. R. A nálise epistemológica das dissertações e teses defendidas no Programa de Pós Graduação em Educação Especial da U FSCar: 1981-2002. 2004. Dissertação (Mestrado em Educação Especial) - Universidade Federal de São Carlos, São Carlos, 2004.

TAWNEY, J. W.; GAST, D. Single subject research in Special Education. Columbus: CharlesE. Merril, 1984.

YADEN , D. B. Reversal designs. In: NEUMAN, S. B.; McCORMIK, S. Singlesubject experimental research: applications for literacy. Delaware: International Reading Association, 1995. p. 32-46. 